\title{
Calcineurin Promotes Neuroplastic Changes in the Amygdala Associated with Weakened Cocaine-Cue Memories
}

\author{
Matthew T. Rich, ${ }^{1,2,3}$ Yanhua H. Huang, ${ }^{1,2}$ and ${ }^{\circledR}$ Mary M. Torregrossa ${ }^{1,2}$ \\ ${ }^{1}$ Department of Psychiatry, ${ }^{2}$ Center for Neuroscience, and ${ }^{3}$ Center for the Neural Basis of Cognition, University of Pittsburgh, Pittsburgh, Pennsylvania \\ 15219
}

Interfering with memory reconsolidation or inducing memory extinction are two approaches for weakening maladaptive memories in disorders such as addiction and post-traumatic stress disorder. Both extinction and reconsolidation are regulated by intracellular protein kinases and phosphatases, and interfering with these signaling molecules can alter memory strength. The calcium-dependent protein phosphatase, calcineurin ( $\mathrm{CaN}$ ), has been implicated in both the consolidation and extinction of fear memories. However, the role of CaN in regulating drug-cue associative memories has not been investigated. Prior studies have demonstrated that plasticity at thalamo-lateral amygdala (T-LA) synapses is critically involved in the regulation of cocaine-cue memories. Therefore, in the present study, we tested the effects of LA administration of an activator of CaN, chlorogenic acid (CGA), on behavioral and electrophysiological indices of cocaine cue memory reconsolidation and extinction. Male, Sprague-Dawley rats were trained to self-administer cocaine paired with an audiovisual cue. The cue memory was then either briefly reactivated, extinguished, or not manipulated, followed immediately by LA infusion of CGA. Rats were tested $24 \mathrm{~h}$ later for cue-induced reinstatement, or LA slices were prepared for electrophysiological recordings. We found that intra-LA infusions of CGA following cue extinction or reconsolidation reduced cue-induced reinstatement, which was blocked by coinfusion of the CaN inhibitor, FK-506. Similarly, CGA infusions following cue re-exposure significantly attenuated EPSC amplitude at T-LA synapses, suggesting that $\mathrm{CaN}$ affects cocaine-cue memory reconsolidation and extinction by altering T-LA synaptic strength. Therefore, CaN signaling in the LA may represent a novel target for disrupting cocaine-associated memories to reduce relapse.

Key words: drug-cue memory; electrophysiology; extinction; pharmacotherapy; reconsolidation; self-administration

\section{Significance Statement}

Repetitive drug use induces synaptic plasticity that underlies the formation of long-lasting associative memories for environmental cues paired with the drug. We previously identified thalamo-amygdala synapses (T-LA) that project via the interal capsule, as an important locus for the regulation of cocaine-cue memories. These synapses are strengthened by repeated cocaine-cue pairings, but this is reversed by extinction training or by optogenetic induction of in vivo long-term depression (LTD). Here, we demonstrate that activating calcineurin, a calcium-dependent phosphatase, following the reactivation or extinction of a cocainecue memory, induces LTD-like changes at T-LA synapses, and a corresponding decrease in cue-induced reinstatement, suggesting that calcineurin may be a potential therapeutic target for relapse prevention.

\section{Introduction}

Addiction is a chronically relapsing disorder for which few effective treatments exist (Kalivas, 2009). Relapse is often driven by

\footnotetext{
Received Feb. 25, 2019; revised Nov. 23, 2019; accepted Dec. 10, 2019.

Author contributions: M.T.R., Y.H.H., and M.M.T. designed research; M.T.R. performed research; M.T.R., Y.H.H., and M.M.T. analyzed data; M.T.R., Y.H.H., and M.M.T. wrote the paper.

This work was supported by United States Public Health Service Grants K01DA031745 (M.M.T.), R01DA042029 (M.M.T.), R01DA035805 (Y.H.H.), F31DA039646 (M.T.R.), T32031111 (M.T.R.), and the Pennsylvania Department of Health. We thank T. Cahanap, A. Miller, and E. Compagnoni for assistance with behavioral experiments, and Y. Wang, R. Guo, and Z. Liu for technical advice.

The authors declare no competing financial interests.

Correspondence should be addressed to Mary M. Torregrossa at torregrossam@upmc.edu.

https://doi.org/10.1523/JNEUROSCI.0453-19.2019

Copyright $\odot 2020$ the authors
}

the re-encountering of environmental contexts and cues that activate memories of prior drug use and initiate feelings of craving (Parvaz et al., 2016). Reducing the strength of drug-associated memories may therefore help promote abstinence. Memory weakening can be accomplished in one of two ways: either interfering with memory reconsolidation or by promoting memory extinction (Torregrossa et al., 2011; Bossert et al., 2013). Reconsolidation is the process of restabilization of a memory after retrieval, which depends upon a cascade of intracellular signaling events and requires protein synthesis. The administration of certain pharmacological agents can prevent memory re-stabilization, thereby weakening or even erasing the memory (Tronson and Taylor, 2007). Whereas reconsolidation is triggered by brief re-exposure 
to conditioned stimuli, the extinction process involves the repeated presentation of a conditioned stimulus in the absence of the expected outcome (e.g., drug reinforcement), which leads to the formation of a new association that the cue is no longer predictive of the outcome. Thus, if drug-related cues are repeatedly presented in the absence of drug reinforcement, a new extinction memory is formed that can inhibit craving and relapse upon subsequent cue re-exposure. (Nader et al., 2000; Holmes and Quirk, 2010; Nic Dhonnchadha et al., 2010).

The lateral amygdala (LA) is critical for the encoding and storage of emotionally-salient memories (Carelli et al., 2003; Shabel and Janak, 2009; Hsiang et al., 2014). The LA receives afferent input from sensory thalamic and cortical sources, as well as inputs from the ventral tegmental area, orbitofrontal, and medial prefrontal cortex, and therefore functions to integrate information during cue-associated learning (Janak and Tye, 2015; Maren, 2016). The LA is activated during both fear- and drug-associated conditioning and during subsequent re-exposure to fear- and drug-related cues (Neisewander et al., 2000; Ciccocioppo et al., 2001; Schafe et al., 2001). Specifically, auditory thalamic synapses (T-LA) are potentiated during reward-associated learning, and we recently found that these synapses are de-potentiated after extinction of a cocaine-cue memory (Tye et al., 2008, Rich et al., 2019).

Extinction and reconsolidation involve similar neural mechanisms, and may be simultaneously activated during cue re-exposure, so timing and selection of the appropriate molecular target for pharmacological manipulation are important considerations. Previous attempts to pharmacologically enhance cue extinction have inadvertently promoted reconsolidation, leading to increased craving (Hofmann et al., 2012; Price et al., 2013). To avoid these unintended consequences, it would be ideal to identify agents that can both disrupt reconsolidation and enhance extinction learning. Here, we investigate the involvement of calcineurin $(\mathrm{CaN})$, a calcium-dependent phosphatase in cocainecue memory extinction and reconsolidation. $\mathrm{CaN}$ is associated with synaptic depotentiation, and the shift from maintenance to inhibition of an auditory fear memory by cue re-exposure is correlated with increased protein levels and enzymatic activity of $\mathrm{CaN}$ in the amygdala (Lin et al., 2003a,b; Merlo et al., 2014). The goal of the present study was to determine whether calcineurin activation would both interfere with the reconsolidation of, and enhance the extinction of, a memory associated with selfadministered cocaine. Based on the prior physiological evidence that T-LA synapses are strengthened by cocaine cue learning and weakened by cue extinction (Rich et al., 2019) we also investigated whether upregulation of $\mathrm{CaN}$ in the LA would alter T-LA synaptic plasticity.

\section{Materials and Methods}

Subjects. Naive, adult male Sprague-Dawley rats (Envigo/Harlan), weighing 275-325 g on arrival, were used for all experiments. Rats were housed in a temperature- and humidity-controlled room, in auto-ventilated racks with an automated watering system. Animals were housed in pairs, given ad libitum access to food and water, and maintained on a $12 \mathrm{~h}$ light/dark cycle. Before surgical procedures, rats were given at least $5 \mathrm{~d}$ to acclimate to the facility. Rats were food-deprived $24 \mathrm{~h}$ before the start of behavioral experiments and maintained at $\sim 90 \%$ of their free-feeding body weight ( $\sim 20 \mathrm{~g}$ of chow/day) for the duration of testing. All behavioral experiments were run during the light cycle. In addition, all procedures were conducted in accordance with the National Institutes of Health Guide for the Care and Use of Laboratory Animals and were approved by the University of Pittsburgh's Institutional Animal Care and Use Committee.
Self-administration test chambers. Rats were trained to self-administer cocaine in standard operant conditioning chambers (Med Associates), described previously (Rich et al., 2016). Experiments were counterbalanced across one of two chamber designs. The inclusion of two chambers allows the reconsolidation group of rats to undergo reactivation in a novel context. The first type of chamber consisted of bar floors and two nose-pokes on one wall, and the second type of chamber had grid floors and the wall with nose-pokes were covered by a dark Plexiglas insert. All chambers contained two retractable levers, a tone-generator, stimuluslight above each lever, house light, and infusion pump. Operant boxes were kept in sound-attenuating chambers equipped with a fan for background noise.

Drugs. Cocaine hydrochloride (generously provided by the National Institute on Drug Abuse) was dissolved in sterile $0.9 \%$ saline $(2 \mathrm{mg} / \mathrm{ml})$ and filter-sterilized for self-administration. Chlorogenic acid (CGA; Fisher Scientific) was dissolved in $1 \times$ PBS to a concentration of 200 $\mathrm{ng} / \mu \mathrm{l}$. CaN inhibitor, FK506 (Sigma-Aldrich) was dissolved in 50\% DMSO to a concentration of $10 \mu \mathrm{g} / \mu \mathrm{l}$.

Surgical procedures. Surgeries were performed as previously described (Rich et al., 2016). Briefly, rats were anesthetized with ketamine hydrochloride $(87.5 \mathrm{mg} / \mathrm{kg}$, i.m.; Henry Schein) and xylazine hydrochloride ( $5 \mathrm{mg} / \mathrm{kg}$, i.m.; Henry Schein) and then received an analgesic (Rimadyl, 5 $\mathrm{mg} / \mathrm{kg}$, s.c.; Henry Schein) and $5 \mathrm{ml}$ of lactated Ringer's (s.c.). Betadine and $70 \%$ ethanol were applied to all incision sites. All rats were implanted with a chronic indwelling intravenous catheter (CamCaths) into the right jugular vein that was fed subcutaneously to the midscapular region, where they exited through a round incision. For experiments involving intracranial infusions, rats were immediately placed into a stereotaxic instrument (Stoelting) and implanted with bilateral stainless-steel guide cannulae (22 gauge; Plastics One) targeting the LA (AP: $-3.0 \mathrm{~mm}, \mathrm{ML}$ : $\pm 5.1 \mathrm{~mm}$, DV: $-7.9 \mathrm{~mm}$, relative to bregma; Paxinos and Watson, 1998). For experiments involving intracranial infusions before electrophysiological recordings, guide cannulae were implanted more dorsal (DV: $-7.2 \mathrm{~mm}$ ) to prevent damage to axon fibers from the internal capsule, which pass through the lateral amygdala. Guide cannulae were secured to the skull with three miniature screws and dental acrylic resin. Rats were then placed on a heating pad for recovery. After surgery, rats were individually housed, and given at least $7 \mathrm{~d}$ to recover before the start of behavioral training. Carprofen $(5 \mathrm{mg} / \mathrm{kg}$, s.c.) was administered for the first $2 \mathrm{~d}$ after surgery. Catheters were kept patent by daily infusions of sterile saline containing gentamicin $(5 \mathrm{mg} / \mathrm{ml})$ and heparin (30 USP/ml).

Self-administration procedures. Rats administered saline or cocaine during daily sessions for $1 \mathrm{~h}$, on a fixed ratio 1 (FR1) schedule of reinforcement with a $10 \mathrm{~s}$ timeout. The designated active lever (counterbalanced across left and right levers) produced a cocaine infusion paired with a $10 \mathrm{~s}$ tone-light compound cue. Pump durations were adjusted daily according to body weight to deliver the correct dose of drug (1.0 $\mathrm{mg} / \mathrm{kg} /$ infusion). Responses on the inactive lever were recorded, but had no programmed consequences. Rats underwent training for at least $10 \mathrm{~d}$ and until they administered at least 8 infusions/d over 3 consecutive days. Rats that did not meet acquisition criteria by $20 \mathrm{~d}$ were excluded from the study. The program was controlled by and data were collected using MedPC (Med Associates).

Instrumental lever extinction. For reinstatement experiments only, after successful acquisition of self-administration, rats underwent instrumental lever extinction (IE) in the self-administer (SA) context for at least $6 \mathrm{~d}$. These sessions lasted for $1 \mathrm{~h}$ and continued until extinction criteria had been met (an average of $<25$ lever presses on the last $2 \mathrm{~d}$ of extinction). Throughout IE, rats received no cocaine or cocaineassociated cue reinforcement. IE was conducted to reduce responding to a stable, low rate to later assess cue-induced reinstatement. In addition, IE reduces the motivational value of other cues in the self-administration context, such as the levers, so that subsequent testing specifically isolates the memory for the discrete cue associated with cocaine infusion.

Pavlovian cue re-exposure procedures. The session occurred $24 \mathrm{~h}$ after the final day of SA or, when included, IE, and lasted for $1 \mathrm{~h}$. During this session, rats received noncontingent presentations of the previously drug-paired cues: either 0 (no extinction), 3 (reactivation/reconsolidation), or 60 (extinction) times. For the reactivation groups, the three 
conditioned stimuli (CS) are presented at the end of the session, assuring that intracranial infusions occur within minutes of memory reactivation. For the "no extinction" and "extinction" groups, this session occurred in the original SA context, but for the "reactivation/reconsolidation" group, this session occurred in the opposite context and included a distinct olfactory cue (almond odor). Extinction occurred in the SA context because of the context dependency of extinction learning, whereas memory reactivation/reconsolidation was conducted in a different context, as some studies suggest that memory retrieval under different or surprising circumstances is necessary to effectively destabilize the memory (Hammond and Wagner, 2013; Torregrossa and Taylor, 2013; Lee et al., 2017).

Intracranial infusions. Immediately following cue re-exposure sessions, rats were removed from the operant boxes, so that the effect of infusions on contextual memories would be mitigated. CGA or vehicle was administered in a volume of $0.5 \mu \mathrm{l} / \mathrm{hemisphere.} \mathrm{CGA} \mathrm{was} \mathrm{given} \mathrm{at} \mathrm{a}$ dose of $100 \mathrm{ng} /$ hemisphere. CGA has not been commonly used for infusion experiments, but this concentration is higher than the dose used in vitro to achieve maximal CaN activity (Tong et al., 2007). For FK506 experiments, rats received one of four infusion mixtures: Veh + Veh, CGA + Veh, Veh + FK506, or CGA + FK506. FK506 was given at a dose of $5 \mu \mathrm{g} / \mathrm{side}$, which is a dose that has previously been administered via intra-hippocampal microinfusions to inhibit $\mathrm{CaN}$ activity and enhance reconsolidation of a contextual fear memory (de la Fuente et al., 2014). Infusions were given by removing dummy cannulae and inserting injection cannulae ( 28 gauge; Plastics One) that extended $1 \mathrm{~mm}$ beyond the guide cannulae. The injectors were connected to Hamilton syringes controlled by a syringe pump via polyethylene tubing. Infusions were given over the course of $2 \mathrm{~min}$ and injectors were left in the cannulae for an additional $1 \mathrm{~min}$ to allow for drug diffusion.

Cue-induced reinstatement. Twenty-four hours after cue memory manipulations, cue-induced reinstatement was assessed during a $1 \mathrm{~h}$ session that took place in the SA context. A lever press on the active lever produced a $10 \mathrm{~s}$ presentation of the cocaine-associated cue on an FR1 schedule, but presses were not reinforced with cocaine. Lever presses on the inactive lever were recorded but had no programmed consequences.

Preparation of ex vivo amygdala slices. Slices were prepared as described previously using methods designed to improve neuronal health in adult rodents (Ting et al., 2014; Rich et al., 2019). Briefly, $24 \mathrm{~h}$ after cue reexposure sessions, rats were deeply anesthetized with isoflurane. Rats were then briefly perfused with ice-cold cutting solution containing the following (in mM): $92 \mathrm{~N}$-methyl-D-glucamine, $2.5 \mathrm{KCl}, 1.2 \mathrm{NaH}_{2} \mathrm{PO}_{4}, 30$ $\mathrm{NaHCO}_{3}, 20$ HEPES, 25 glucose, 5 sodium ascorbate, 2 thiourea, 3 sodium pyruvate, $10 \mathrm{MgSO}_{4}$, and $0.5 \mathrm{CaCl}_{2}$, saturated with carbogen $(95 \%$ $\mathrm{O}_{2} / 5 \% \mathrm{CO}_{2}$ ), $\mathrm{pH}$ adjusted to 7.4 with $\mathrm{HCl}$. Rats were then decapitated and brains removed. Acute coronal slices of the amygdala ( $250 \mu \mathrm{m}$ thick) were obtained (normally $4-6$ slices were obtained from each rat) using a VT1200S vibratome (Leica) in $4^{\circ} \mathrm{C}$ cutting solution. Slices were placed in a holding chamber filled with the same cutting solution, and incubated at $37^{\circ} \mathrm{C}$ for $10-15 \mathrm{~min}$ before being transferred to a beaker of HEPES-based holding solution containing the following (in $\mathrm{mm}$ ): $86 \mathrm{NaCl}, 2.5 \mathrm{KCl}, 1.2$ $\mathrm{NaH}_{2} \mathrm{PO}_{4}, 35 \mathrm{NaHCO} 3,20$ HEPES, 25 glucose, 5 sodium ascorbate, 2 thiourea, 3 sodium pyruvate, $1 \mathrm{MgCl} 2$, and $2 \mathrm{CaCl} 2$, saturated with carbogen. Slices were allowed to recover for $>30 \mathrm{~min}$ at room temperature before experimentation.

Ex vivo electrophysiology. Slices were transferred to an Olympus BX51WI upright microscope equipped with Dodt Gradient Contrast infrared optics. The LA was identified using a $4 \times$ objective and this region was then magnified for identification of neurons with a $40 \times$ water-immersion lens. Principal neurons were identified by morphology, and in voltage-clamp, typically showing low levels of spontaneous activity. All experiments used pipettes filled with a cesium-based internal solution (in mM: 108 cesium methanesulfonate, $15 \mathrm{CsCl}$, 0.4 CsEGTA, 5 TEA-Cl, 20 HEPES, 2.5 Mg-ATP, 0.25 Na-GTP, 1 QX-314-Cl, 7.5 sodium phosphocreatine, and $1 \mathrm{~L}$-glutathione, $\mathrm{pH} 7.3$ with $\mathrm{CsOH}$ ). During recordings, slices were superfused with a modified artificial CSF (aCSF), containing the following (in $\mathrm{mm}[\mathrm{SCAP}]$ ): $119 \mathrm{NaCl}, 2.5 \mathrm{KCl}, 26 \mathrm{NaHCO}$, $1.2 \mathrm{NaH}_{2} \mathrm{PO}_{4}, 12.5$ glucose, $5 \mathrm{HEPES}, 1 \mathrm{MgSO}_{4}, 2 \mathrm{CaCl}_{2}$, saturated with $95 \% \mathrm{O}_{2} / 5 \% \mathrm{CO}_{2}$ (Ting et al., 2014; Rich et al., 2019). aCSF was heated to $31-33^{\circ} \mathrm{C}$ by passing the solution through a feedback-controlled in-line heater (Warner) before entering the chamber. For all recordings, neurons were voltage-clamped at $-70 \mathrm{mV}$. A concentric bipolar stimulating electrode (FHC) was placed over axon fibers emerging from the internal capsule (putative thalamic afferents; Rich et al., 2019). Evoked EPSCs were recorded by stimulating projections to the LA $(0.1 \mathrm{~ms}$ pulses at 0.1 $\mathrm{Hz})$ at predetermined series of intensities $(10-35 \mu \mathrm{A})$ using an isolated constant current stimulator (A-M Instruments; DS3, Digitimer). Picrotoxin $\left(100 \mu \mathrm{M}\right.$; dissolved in DMSO) was included to inhibit $\mathrm{GABA}_{\mathrm{A}}$ receptor-mediated currents in all experiments. For paired-pulse delivery, each pulse was separated by a $50 \mathrm{~ms}$ interpulse interval. AMPAR currents were elicited at reversal potential $\left(E_{\mathrm{Rev}}\right)-70 \mathrm{mV}$ holding potential and mixed AMPAR+NMDAR currents were elicited at a $E_{\mathrm{Rev}}+40 \mathrm{mV}$ holding potential. NMDAR amplitude was operationally defined as the amplitude of the $E_{\mathrm{Rev}}+40 \mathrm{mV}$ current $35 \mathrm{~ms}$ after the peak of the AMPAR current $\left(E_{\mathrm{Rev}}-70 \mathrm{mV}\right)$; at this time point, AMPAR-mediated currents have subsided (Huang et al., 2008, 2009). For all experiments, series resistance was $15-25 \mathrm{M} \Omega$, uncompensated, and monitored continuously during recording. Cells with a change in series resistance beyond $20 \%$ were not accepted for data analysis. Synaptic currents were recorded with a MultiClamp 700B amplifier (Molecular Devices), filtered at $3 \mathrm{kHz}$, amplified five times, and then digitized at $20 \mathrm{kHz}$.

Histological analysis. After the completion of behavioral experiments, rats with intracranial cannulae were killed via decapitation. Brains were dissected and placed in $10 \%$ formalin for at least $3 \mathrm{~d}$ then transferred to $30 \%$ sucrose for at least $3 \mathrm{~d}$. Brains were then frozen and sectioned coronally through the basolateral amygdala (BLA) on a cryostat. Sections were taken at $50 \mu \mathrm{m}$ and placed on slides for visualization of infusion placements (Fig. 1D). The investigator was blind to treatment group when analyzing histology, and animals with infusions outside of the BLA in at least one hemisphere were removed from the final analysis. Although a minority of placements appear to fall along the borders of dorsal basal amygdala and lateral central amygdala, it should be noted that all placement markings are best estimates.

Experimental design and statistical analyses. All statistical analyses were performed using GraphPad Prism for Windows or JMP Pro for Macintosh, and results are expressed as mean \pm SEM. Rats were distributed into groups based on a matching procedure that ensured that each group had no statistical differences in their cocaine infusions or active and inactive lever responses over days as well as no differences in lever extinction behavior. For behavioral experiments, reinstatement tests were analyzed by multifactor ANOVA with repeated measures, with the within-subjects factor being responding on the last day of lever extinction versus reinstatement responding and the between-subjects factor being CGA versus Veh. For electrophysiological experiments, data were coded such that experimenters were not aware of treatment groups when performing data analysis, and then decoded for final results. Although not always possible for experimenters to be blind to condition during recordings, a standard protocol was used for all sessions. Data were analyzed off-line using Clampfit 10.3. For experiments in which the endpoints were from individual cells, such as EPSCs, we used the averaged value of a parameter from all cells recorded from an animal to represent the parameter of this animal. For electrical stimulation experiments, EPSC amplitude was calculated at each stimulation intensity and compared between groups using two-way ANOVA with repeated measures. Paired-pulse ratio (PPR) was calculated as the ratio of the peak current of the second EPSC to the peak current of the first EPSC. AMPA-NMDA ratio was calculated as the ratio of peak current at $-70 \mathrm{mV}$ to the current at $+40 \mathrm{mV}, 35 \mathrm{~ms}$ after stimulus. For, PPR, AMPA-NMDA ratio, AMPAR, and NMDAR current analyses, comparisons were made using unpaired two-tailed $t$ tests. All data points are an average of 10 trials. Each experiment was replicated in at least 5-6 rats ( $1-5$ cells were recorded from each rat) for electrophysiological analysis and at least 7 rats for behavioral tests. For all analyses, significant effects were further analyzed by Tukey's or Bonferroni's post hoc tests, with significance set at $p<0.05$. All data were determined to be normally distributed using the Shapiro-Wilk test, and Bartlett's test was used to determine that there were no significant differences in the estimated variance between groups. 

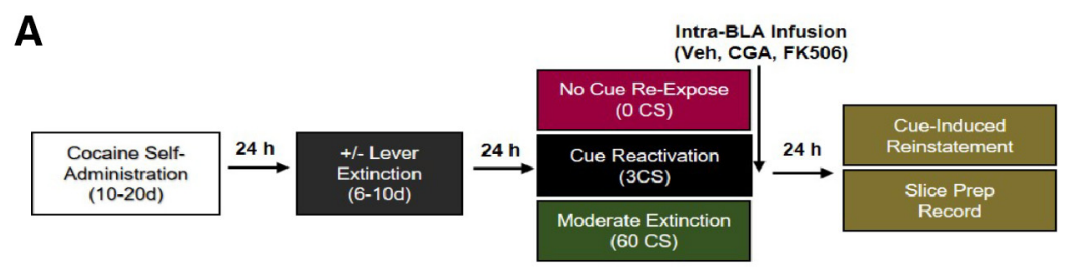

B

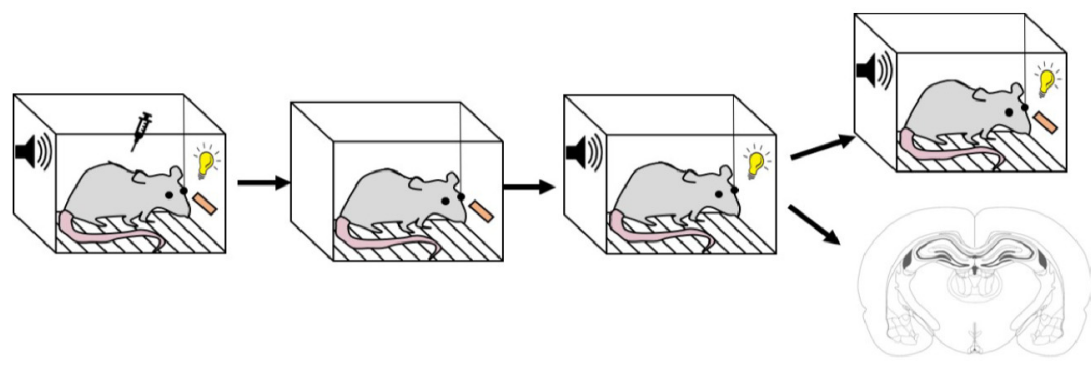

C

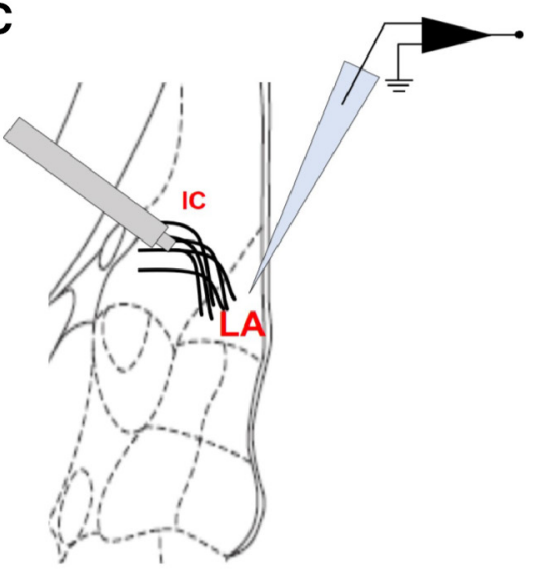

Figure 1. Experimental design. Schematic representation of $(\boldsymbol{A})$ timeline of each experimental phase and color-coded treatment groups, $(\boldsymbol{B})$ diagram of operant chamber with visual depiction demonstrating specific contingencies of each experimental stage, and $(\boldsymbol{C})$ schematic of LA coronal section demonstrating electrophysiology experimental design, with placement of stimulating electrode above internal capsule (IC) fibers and position of patch pipette. EPSCs were evoked from LA principal neurons by stimulating the IC (putative T-LA synapses).

\section{Results}

To determine whether $\mathrm{CaN}$ in the LA was involved in the regulation of cocaine-cue memory we used an approach that combined in vivo pharmacological activation of $\mathrm{CaN}$ with specific cue memory manipulations followed by behavioral and electrophysiological assessments. Rats were trained to SA cocaine on a FR1 schedule of reinforcement, so that a single press on a predesignated active lever resulted in an intravenous cocaine infusion together with presentation of an audiovisual cue (CS). Following SA, for reinstatement experiments, rats underwent IE (Fig. 1A,B). During IE, rats were allowed to perform operant responses; however, presses on the active lever were no longer reinforced by either cocaine or CS presentation. Although this extinguishes the operant response, the cocaine-cue association remains, so that future presentations of the CS can promote reinstatement of the lever pressing response (Torregrossa and Taylor, 2013). Importantly, for all experiments there were no group differences in the number of extinction sessions needed to reach extinction criteria. For electrophysiology experiments, IE was omitted because our previous experiments show that T-LA synaptic plasticity is not affected by IE (Rich et al., 2019). Rats were next assigned to one of three memory manipulation groups and exposed to passive presentations of CS: no reactivation (0 CS), cue reactivation (3 CS), or cue extinction ( $60 \mathrm{CS}$; Fig. $1 A, B$ ). Immediately following these sessions, rats received intra-LA microinfusions of the CaN activator, CGA (100 ng/hemisphere; Tong et al., 2007), or vehicle (Veh) to determine what effect CaN activation has on cocainecue memory processes. Finally, $24 \mathrm{~h}$ later, rats either received a cue-induced reinstatement test or ex vivo slices of the LA were prepared for electrophysiological recordings (Fig. 1A,B). For reinstatement, rats returned to the original SA context and received response-contingent presentations of CS, but not cocaine. A high degree of lever pressing during reinstatement is suggestive of an intact cocaine-cue association, while low levels of lever pressing indicate that the cocaine-cue association has been disrupted. For electrophysiological recordings, whole-cell voltage-clamp recordings were performed from LA principal neurons. EPSCs were evoked by stimulating internal capsule fibers, which largely carry auditory thalamic inputs (Rich et al., 2019; although it is also possible that visual thalamic inputs may be recruited as well), to target putative T-LA synapses (Fig. 1C). Using a predetermined series of stimulation intensities, we generated EPSC input-output relationships. We also compared measures of presynaptic and postsynaptic plasticity. This strategy enables a direct comparison between T-LA synaptic activity and cocaine-cue memory and allows for the assessment of the role of $\mathrm{CaN}$-induced plasticity in mediating relapse-like behavior.

\section{Effect of intra-LA CaN activation during cocaine-cue memory reconsolidation}

First, we investigated whether activating $\mathrm{CaN}$ in the LA immediately following cocaine-cue memory reactivation (3 CS) would alter subsequent cue-induced drug-seeking. Because $\mathrm{CaN}$ is a negative regulator of fear-memory reconsolidation (de la Fuente et al., 2014; Merlo et al., 2014) we hypothesized that activating CaN following cue reactivation would interfere with reconsolidation of the cocaine-cue memory. The resulting disruption of the cocaine-cue association would suppress the conditioned response (lever pressing) to subsequent cue presentations, thereby attenuating reinstatement. Further, based on the ability of $\mathrm{CaN}$ to promote synaptic depotentiation (Lin et al., 2003a,b), and because reconsolidation is regulated by opposing LTP-like mechanisms, we predicted that CGA-mediated decreases in reinstatement would be associated with reductions in AMPAR-mediated signaling. For both sets of experiments, rats were split into groups based on a random matching procedure that ensured no significant differences between groups or interactions with day of training for active lever presses during SA or IE (Fig. $2 A, B ; \mathrm{SA}: F_{(1,20)}=0.328$, $p>0.05$; IE: $\left.F_{(1,20)}=0.152, p>0.05\right)$. For both SA and IE, there was a main effect of training day (Fig. $2 A, B$; SA: $F_{(9,180)}=4.516$, $p<0.001$; IE: $\left.F_{(6,120)}=28.15, p<0.001\right)$, indicating appropriate acquisition of SA followed by extinction of instrumental responding. When comparing the effect of CGA treatment on lever responding (Fig. 2C), we found that treatment with CGA following cue reactivation had no effect on inactive lever responding (data not shown), but did reduce active lever responding during 
A

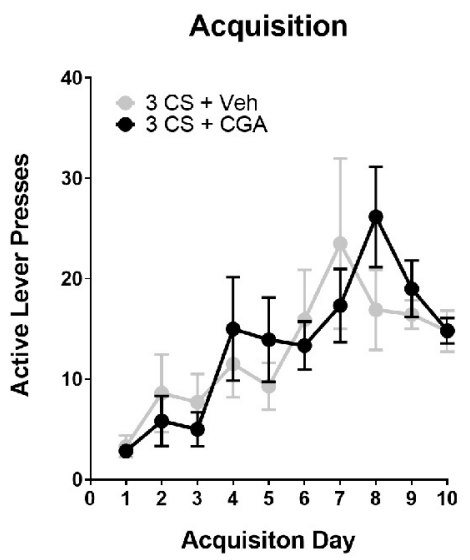

B

Instrumental Extinction

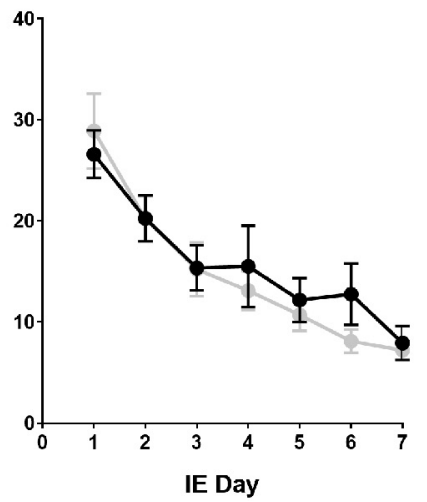

C

Effect of CaN Activation on Reinstatement

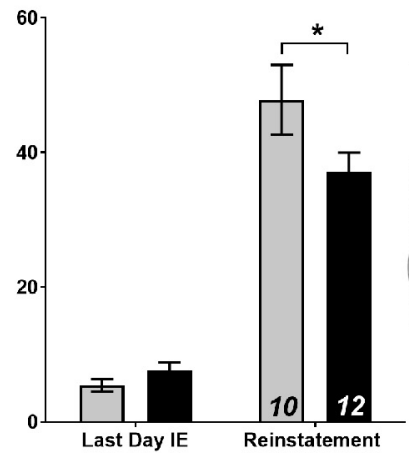

$-2.92$

$-3.00$

$-3.12$

$-3.24$

Figure 2. Calcineurin activation following cue reactivation inhibits reconsolidation and attenuates subsequent cue-induced reinstatement. $\boldsymbol{A}, \boldsymbol{B}$, Mean number of active lever presses per day during SA and IE. There were no significant differences in active lever presses during $(\boldsymbol{A}) \mathrm{SA}$ or $(\boldsymbol{B}) \mathrm{IE}$. Following IE, rats were placed back in training context and received a brief cue-reactivation ( 3 CS) session followed immediately by infusion with either GGA or Veh. $C$, Mean number of active lever presses during the last day of instrumental extinction compared with cue-induced reinstatement. CGA activation following 0 CS reduces active lever responding during reinstatement. Inset, Histological verification of guide cannulae placements throughout the anterior-posterior extent of the LA. For this and all future histological figures, the blue shaded circles represent acceptable cannulae placement in both hemispheres for all rats used in final analysis. Rats that received cannulae implants outside of these regions (black Xs) or hits only in one hemisphere (blue open circles) are also depicted. Coordinates are in millimeters, posterior from bregma. Data are expressed as mean \pm SEM; $n$ in bars, number of rats. ${ }^{*} p<0.05$.

cue-induced reinstatement, indicating that pharmacological manipulation of $\mathrm{CaN}$ signaling disrupts reconsolidation (Fig. 2C; significant group $\times$ day interaction: $\left.F_{(1,20)}=4.790, p=0.041\right)$.

Next, we determined whether the suppression in cue-induced reinstatement was associated with $\mathrm{CaN}$-dependent alterations at T-LA synapses. First, we found that CGA-induced activation of CaN caused a reduction in the EPSC input-output relationship at T-LA synapses (Fig. 3A; significant group $\times$ stimulation intensity interaction: $\left.F_{(5,70)}=2.373, p=0.048\right)$. At the highest stimulation intensity $(35 \mu \mathrm{A})$, CGA-treated animals had significantly lower EPSC amplitude compared with Veh-treated animals (Veh: $480 \pm$ $44.1 \mathrm{pA}$; CGA: $392 \pm 29.7 \mathrm{pA}$ ). These data suggest a synaptic basis for the disruption in reconsolidation produced by CGA that suppressed drug-seeking behavior. Next, we examined whether a presynaptic or postsynaptic mechanism could explain the reduced synaptic strength. We observed no group differences in PPR (Fig. 3B; unpaired $t$ test, $p>0.05$ ). However, CGA infusion resulted in a significant reduction in AMPA-NMDA ratio (Fig. $3 C$; unpaired $t$ test, $\left.t_{(14)}=2.316, p=0.036\right)$. Upon further examination, it became apparent that this reduction was driven by changes in AMPAR, because average AMPAR current was significantly reduced by CGA (Fig. $3 D$; unpaired $t$ test, $t_{(14)}=2.653$, $p=0.019)$, while there was no difference in NMDAR current (Fig. 3E; unpaired $t$ test, $p>0.05$ ). Together, these data suggest that following cocaine-cue memory reactivation, CGA infusion leads to postsynaptic reductions in AMPAR that interfere with reconsolidation.

\section{Effect of intra-LA CaN activation during cocaine-cue memory extinction}

Next, we tested the effects of CGA-induced CaN activation following cocaine-cue memory extinction (60 CS). We hypothesized that extinction would be enhanced by CGA; specifically, we predicted that cue extinction is mediated by CaN activity. Therefore, an upregulation of CaN activity by CGA would further promote the molecular signaling events that lead to extinction of the original cocaine-cue association, resulting in an even more pronounced attenuation in active lever pressing during cue-induced reinstatement. As with the reconsolidation experiment, we predicted that a suppression in cue-induced reinstatement would be caused by CaN-dependent modifications at T-LA synapses. Again, rats were split into groups so that there were no significant differences between groups or interactions with day of training for active lever presses during SA or IE (Fig. $4 A, B$; SA: $F_{(1,17)}=0.179$, $p>0.05$; IE: $\left.F_{(1,17)}=1.353, p>0.05\right)$, and appropriate acquisition and instrumental extinction was confirmed (Fig. 4A, $B$; SA: $F_{(9,153)}=2.998, p=0.003$; IE: $\left.F_{(6,102)}=29.39, p<0.001\right)$. When comparing the effect of CGA treatment on lever responding during reinstatement, there was again no effect on inactive lever responding (data not shown), but there was an effect on active lever responding (Fig. 4C). We found a main effect of treatment $\left(F_{(1,17)}=6.879, p=0.018\right)$ and a main effect of test day $\left(F_{(1,17)}=\right.$ $100.6, p<0.001)$, the interaction was not statistically significant $\left(F_{(1,17)}=3.150, p=0.094\right)$, likely because of the fact that the "to-be CGA group" tended to respond less on the last day of extinction as well. We performed the experiment again, and to rule out any nonspecific effects of CGA, we combined intra-LA CGA infusions with a known inhibitor of CaN, FK-506 (de la Fuente et al., 2014). Rats again received cue extinction, but this time received one of four infusions (Veh-Veh, CGA-Veh, VehFK-506, CGA-FK-506) after the session, and were tested for reinstatement the following day. Analysis by MANOVA revealed a significant effect of test day (Fig. $\left.4 D ; F_{(1,33)}=187.24, p<0.001\right)$, a significant effect of CGA treatment $\left(F_{(3,33)}=3.04, p=0.043\right)$, but not a significant interaction between CGA and FK506 treatment $\left(F_{(3,33)}=1.73, p=0.181\right)$. Inspection of the data suggests that CGA-infusion alone resulted in a reduction in reinstatement, similar to our findings from Figure $4 C$, and that in the presence of FK-506, this effect was mitigated. However, given that neither interaction reached statistical significance, we did not perform post hoc tests. Nevertheless, the consistency of reduced cue-induced reinstatement in the CGA-treated groups across both experiments and the large effect size when comparing CGA to vehicle treatment (Hedge's $g=1.08$ and 1.52, respectively) suggests that CGA has some ability to facilitate cue extinction learning through activation of calcineurin. 


\section{A IC Stimulation}

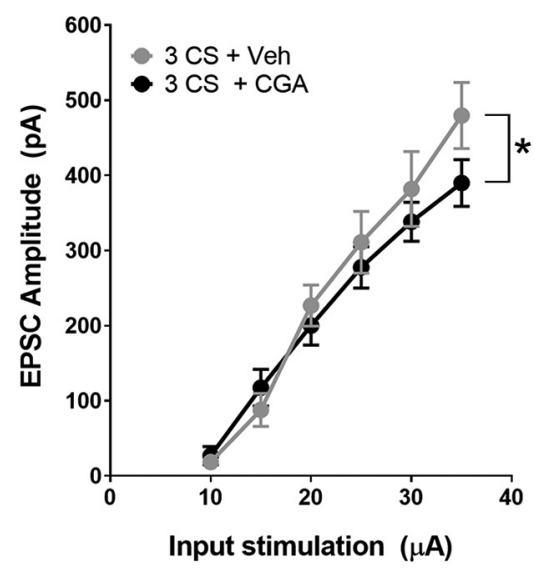

C

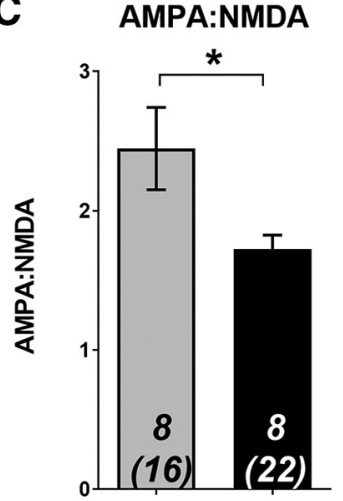

$3 \mathrm{CS}+\mathrm{Veh} \quad 3 \mathrm{CS}+\mathrm{CGA}$

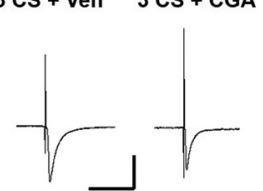

B

Paired Pulse Ratio
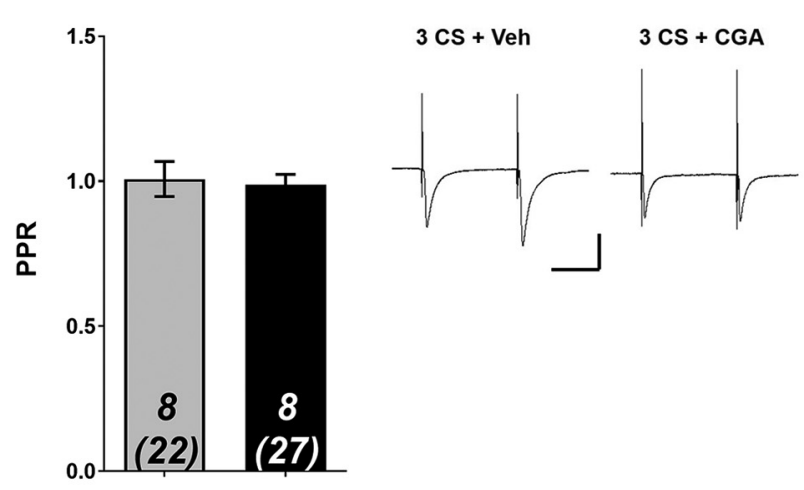

E

NMDA
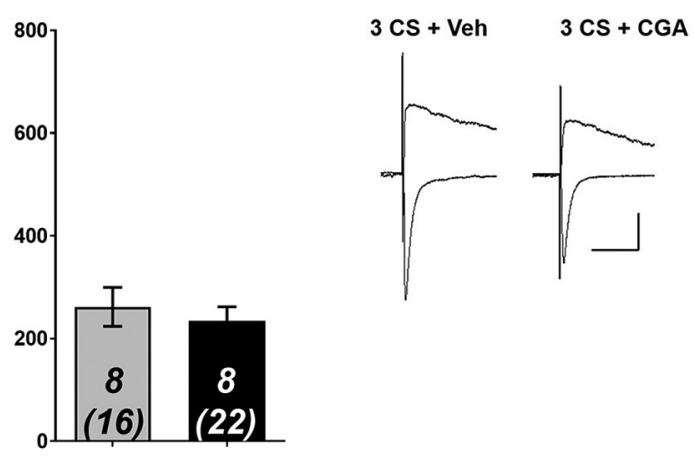

Figure 3. Calcineurin activation during reconsolidation alters synaptic plasticity through a postsynaptic reduction in AMPAR current. Following $S A$, rats received a brief cue reactivation (3 CS) session followed immediately by infusion with either CGA or Veh. Twenty-four hours later, ex vivo recordings were performed in the LA. $\boldsymbol{A}$, Input/output curve demonstrating average evoked EPSC amplitude across various stimulation intensities. Intra-LA CaN activation by CGA decreases EPSC amplitude. $\boldsymbol{B}$, No significant differences in PPR between groups. CaN activation by CGA significantly reduced (C) AMPA-NMDA and (D) AMPA current, but had no effect on $(\boldsymbol{E})$ NMDA current. Data are expressed as mean \pm SEM; $n$ in bars, number of rats (number of neurons). ${ }^{*} p<0.05$. Insets, Sample average EPSC traces. Scale bars: $50 \mathrm{~ms}, 200 \mathrm{pA}$.

Although CaN activation following moderate CS re-exposure failed to significantly reduce relapse-like behavior following cue extinction, this did not rule out the possibility that CGA infusions could still induce T-LA synaptic alterations. Indeed, we found that CGA-induced activation of CaN during cue extinction caused a reduction in the EPSC input-output relationship at T-LA synapses (Fig. 5A; significant group $\times$ stimulation intensity interaction: $\left.F_{(5,75)}=1.497, p=0.037\right)$. At the highest stimulation intensity $(35 \mu \mathrm{A})$, CGA-treated animals had significantly lower average EPSC amplitude than Veh-treated animals (Veh: $318 \pm 26.2 \mathrm{pA}$ vs CGA: $237 \pm 30.2 \mathrm{pA}$ ). The EPSC amplitudes of the vehicle group are consistent with previous results, in which 60 CS reexposure partially de-potentiated cocaine-induced T-LA plasticity, whereas the CGA group had EPSC amplitudes similar to 120 CS extinction (Rich et al., 2019). These data suggest a T-LA synaptic mechanism for extinction learning that suppresses relapse-like behavior, as well as a potential for the involvement of CaN. We further examined whether a presynaptic or postsynaptic mechanism could explain the observed reduction in synaptic strength. Surprisingly, CGA-induced activation of $\mathrm{CaN}$ during cue extinction increased PPR (Fig. 5B; unpaired $t$ test, $t_{(15)}=3.284, p=$ $0.005)$, suggestive of a presynaptic suppression of transmission. On the other hand, AMPA-NMDA ratio was not significantly altered by CGA infusion (Fig. $5 C$; unpaired $t$ test, $t_{(13)}=1.777$, $p=0.099$ ). These results are in contrast to our findings from the reconsolidation experiment, indicating that a presynaptic signal- ing mechanism (i.e., suppression of glutamate release) is primarily responsible for CaN-induced reductions in T-LA synaptic strength that may facilitate cocaine-cue memory extinction. Still, based on the CGA-induced reduction in the EPSC input-output relationship as well as a strong trend for reduced AMPA-NMDA ratio, a postsynaptic mechanism cannot be completely ruled out.

Effect of intra-LA CaN activation in the absence of cocaine-cue memory retrieval

Finally, we wanted to ensure that LA CaN activation did not produce nonspecific effects in the absence of cocaine-cue memory retrieval (0 CS re-exposure). Previous studies have shown that amnestic agents are ineffective at inhibiting memories if they are not reactivated or retrieved; because the memory does not enter a destabilized or labile state (Tronson et al., 2006; Rich et al., 2016). Therefore, we predicted that CGA-induced activation of CaN would have no effect on reinstatement or T-LA synaptic plasticity in the absence of retrieval. As with the other experiments, rats were split into groups to ensure no training differences during SA or IE. (Fig. $6 A, B$; SA: $F_{(1,20)}=0.343, p>0.05$; IE: $\left.F_{(1,20)}=0.286, p>0.05\right)$. Unlike the cue-memory reconsolidation and extinction experiments, we found that treatment with CGA following the no-reactivation control procedure had no significant effect on active lever responding during cue-induced reinstatement (Fig. $6 C$; main effect of test day: $F_{(1,20)}=70.42, p<$ 0.001 ; but no main effect of treatment: $\left.F_{(1,20)}=0.286, p>0.05\right)$, 
indicating that pharmacological manipulation of $\mathrm{CaN}$ signaling has no effect on cocaine seeking in the absence of cue memory retrieval.

We next assessed whether intra-LA infusion of CGA in the absence of memory retrieval would alter T-LA synaptic strength, and as expected, found no differences between CGA- and Veh-treated animals for any measure of synaptic plasticity. EPSC input-output relationships did not vary between groups (Fig. 7A). At the highest stimulation intensity $(35 \mu \mathrm{A})$, Veh- and CGA-groups had average EPSC amplitudes of $376 \pm 65.1$ and $375 \pm 26.1 \mathrm{pA}$, respectively, which is consistent with our previous studies for animals in the no cue re-exposure condition (Rich et al., 2019), and higher than the levels observed in the 60 CS extinction group (Fig. 5). Similarly, we saw no differences in PPR, AMPANMDA, AMPAR current, or NMDAR current (Fig. $7 B-E$; all unpaired $t$ test, $p>$ $0.05)$. Together, these data suggest that in the absence of memory retrieval, attempted activation of CaN by CGA produces no alterations in T-LA presynaptic or postsynaptic plasticity, corresponding to the lack of difference in cue-elicited drug-seeking.

\section{Discussion}

The present study identifies a link between CaN-induced activity at T-LA synapses and the suppression of cue-elicited cocaineseeking. Specifically, activation of CaN, during either reconsolidation or extinction of a memory associated with cocaine self-administration led to synaptic modifications that resulted in reduced cue-induced reinstatement, effectively disrupting the drug-associated memory. These results are consistent with both a partial inhibition of reconsolidation of the original cocaine-cue memory and potentially an enhancement in the new cocaine-cue extinction memory. Importantly, in the absence of memory retrieval, CaN activation had no memory-interfering effects, confirming that the memory trace must be reactivated to achieve pharmacologicallyinduced disruption. We have previously found similar behavioral effects following intra-BLA infusion of CaMKII inhibitors (Rich et al., 2016), suggesting that CaN and CaMKII within the BLA have opposing actions on drug-associated memory processes. Furthermore, T-LA synapses are differentially regulated by consolidation/reconsolidation and extinction of a cocaine-cue memory (Rich et al., 2019). Although possible that input arising from visual thalamus is also recruited, optogenetic depotentiation of
A

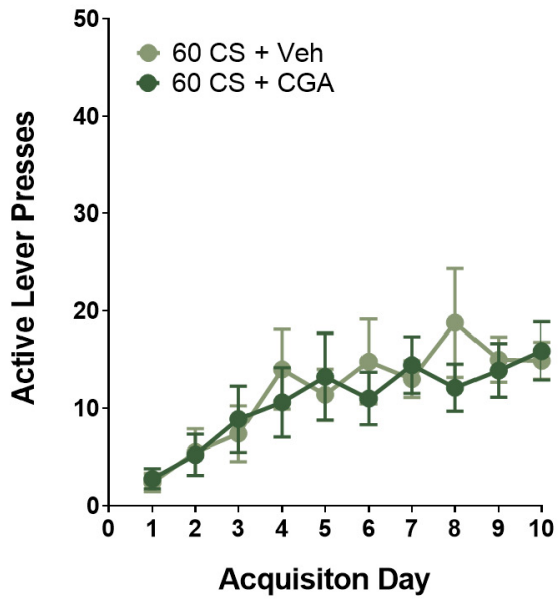

C

Acquisition

\section{Effect of CaN Activation on Reinstatement}

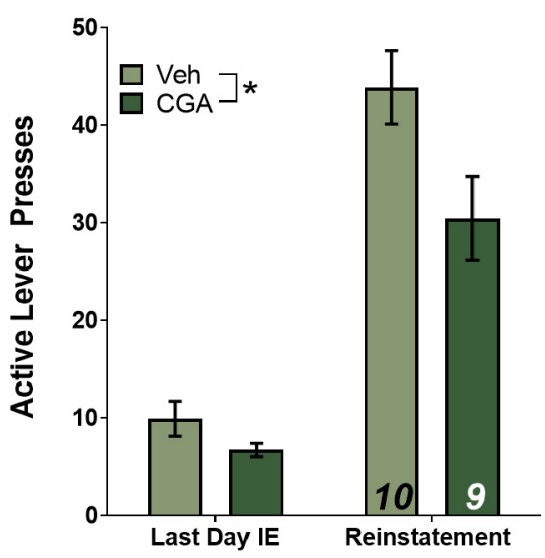

D

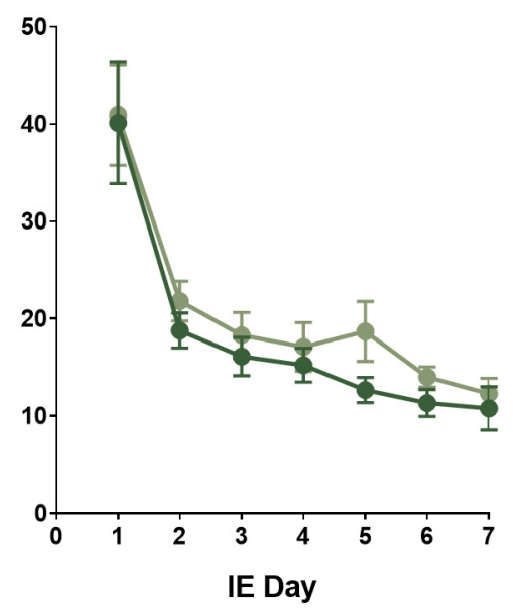

B Instrumental Extinction

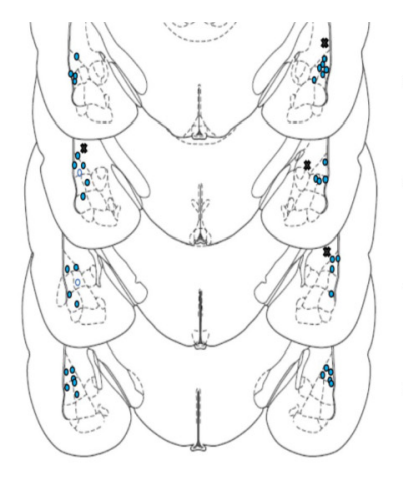

$-2.92$

$-3.00$

$-3.12$

$-3.24$

\section{Calcineurin Inhibition Blocks CGA Effects}

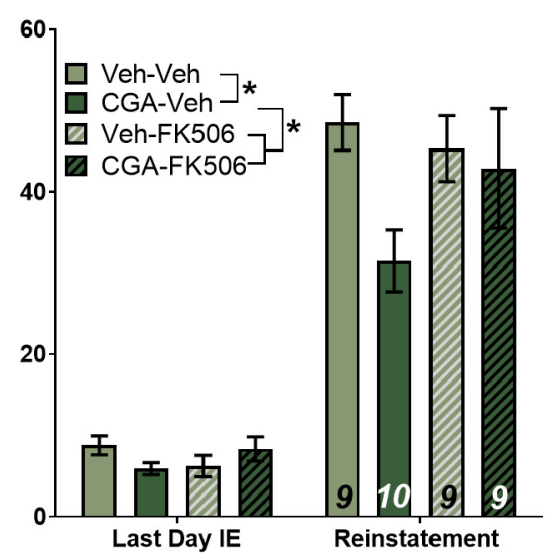

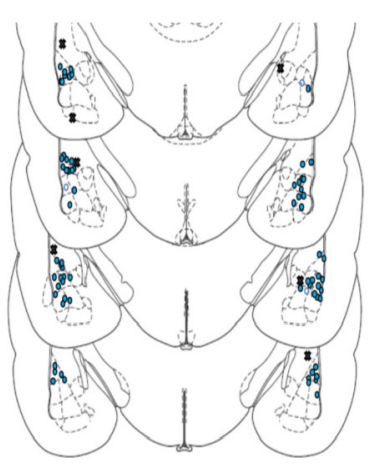

$-2.92$

Figure 4. Activating calcineurin during cue extinction fails to significantly reduce subsequent cue-induced reinstatement. $\boldsymbol{A}, \boldsymbol{B}$, Mean number of active lever presses per day during SA and IE. There were no significant differences in active lever presses during $(\boldsymbol{A}) \mathrm{SA}$ or $(\boldsymbol{B}) \mathrm{IE}$. Following IE, rats were placed back in training context and received a cue-extinction (60 CS) session followed immediately by infusion with either (GA or Veh. $\boldsymbol{C}$, Mean number of active lever presses during the last day of instrumental extinction compared with cue-induced reinstatement. CGA activation following $60 \mathrm{CS}$ does not significantly reduce active lever responding during reinstatement. $\boldsymbol{D}$, Effect of CGA on extinction is mitigated by co-infusion of CaN inhibitor, FK-506. Insets, Histological verification of guide cannulae placements throughout the anterior-posterior extent of the LA. Data are expressed as mean \pm SEM; $n$ in bars, number of rats. ${ }^{*} p<0.05$. 
A

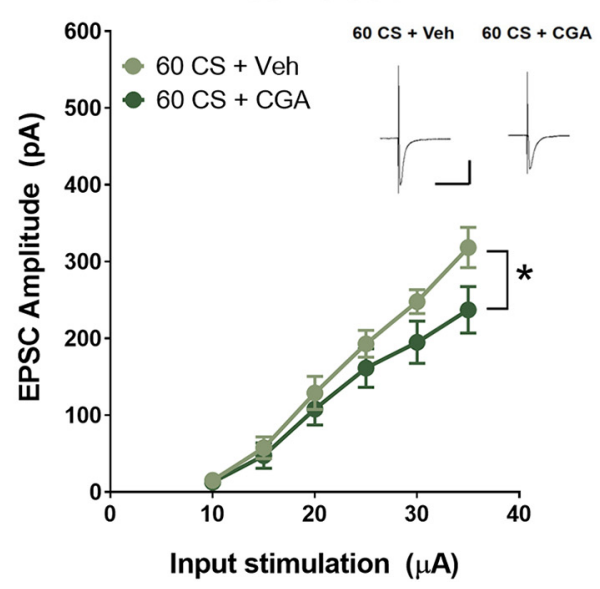

B Paired Pulse Ratio

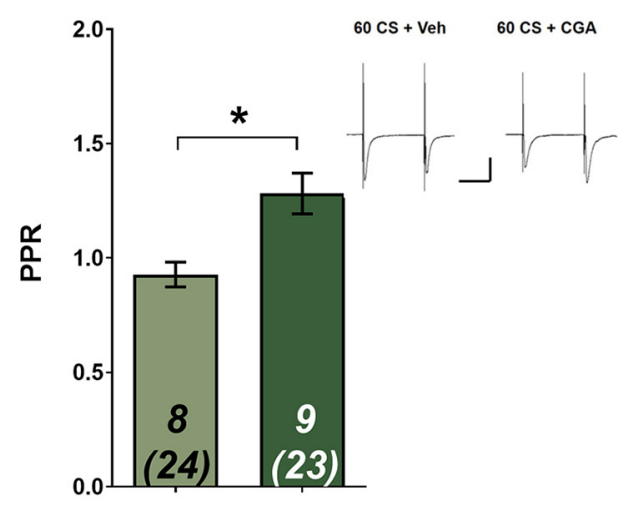

C AMPA:NMDA

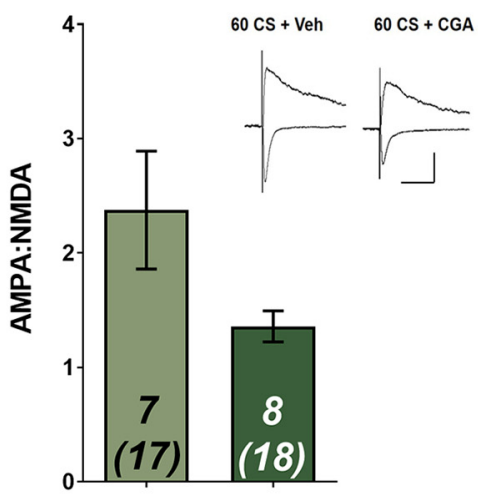

Figure 5. Calcineurin activation during cue extinction alters synaptic plasticity through a presynaptic mechanism. Following SA, rats received a cue-extinction (60 CS) session followed immediately by infusion with either CGA or Veh. Twenty-four hours later, ex vivo recordings were performed in the LA. $A$, Input/output curve demonstrating average evoked EPSC amplitude across various stimulation intensities. Intra-LA CaN activation by CGA reduces EPSC amplitude. $\boldsymbol{B}$, CGA infusion significantly increases PPR. CaN activation by CGA does not significantly alter ( $\boldsymbol{C}$ ) AMPANMDA. Data are expressed as mean \pm SEM; $n$ in bars, number of rats (number of neurons). ${ }^{*} p<0.05$. Insets, Sample average EPSC traces. Scale bars: 50 ms, 200 pA.

A

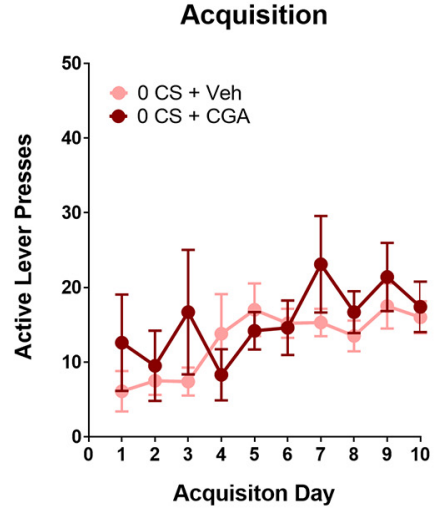

B Instrumental Extinction

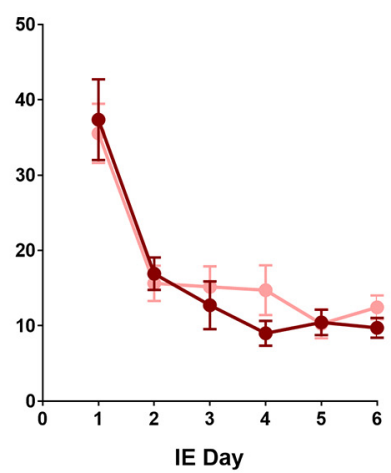

C

Effect of CaN Activation on Reinstatement

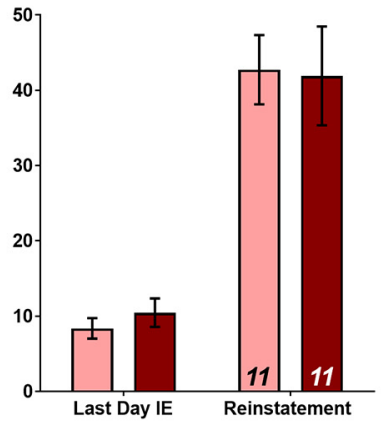

$-2.92$ $-3.00$ $-3.12$ $-3.24$

Figure 6. Calcineurin activation has no effect on cue-induced reinstatement in the absence of memory retrieval. $A, B$, Mean number of active lever presses per day during $S A$ and IE. There were no significant differences in active lever presses during $(\boldsymbol{A}) \mathrm{SA}$ or $(\boldsymbol{B}) \mathrm{IE}$. Following IE, rats were placed back in training context and received a no-reactivation $(0 \mathrm{CS})$ session followed immediately by infusion with either CGA or Veh. C, Mean number of active lever presses during the last day of instrumental extinction compared with cue-induced reinstatement. CGA activation following 0 CS has no effect on reinstatement. Inset, Histological verification of guide cannulae placements throughout the anterior-posterior extent of the LA. Data are expressed as mean \pm SEM; $n$ in bars, number of rats.

specific afferents from the medial geniculate nucleus attenuated cue-induced reinstatement.

To our knowledge this study is the first report of pharmacologically-induced changes in synaptic activity that are directly associated with changes in the conditioned response to drugassociated cues. Upregulation of CaN activity following cue retrieval induces postsynaptic changes, perhaps driven by activity at AMPAR that prevents the memory-maintenance/strengthening effects of reconsolidation and attenuates reinstatement. Similarly, although cue extinction alone induces postsynaptic depotentiation via reductions in AMPAR and NMDAR signaling, upregulation of CaN activity following cue extinction appears to alter presynaptic signaling as well, perhaps via a decreased glutamate release probability. Together, CaN-dependent synaptic changes appear to influence the propensity of cues to trigger relapse-like behaviors.

\section{Targeting memory processes as a strategy for relapse prevention}

Interfering with memories that trigger drug-seeking can assist in the maintenance of long-term abstinence, however, this strategy has had limited success in preventing relapse (Koob and Volkow, 2010). Clinical studies have attempted to use cue extinction as a means to interfere with drug-related memories by re-exposing individuals to multimodal cues in an effort to decrease subsequent craving and relapse when the drug-associated cues were re-encountered (Price et al., 2013). Unfortunately, extinction of drug-associated memories in this manner has not yielded clinical success. It is possible that combining behavioral therapies, like extinction, with pharmacological treatments may overcome the limitations of traditional cue extinction therapies. Indeed, this approach has been demonstrated to have the highest success rates (Carroll and Onken, 2005) and, to date, preclinical studies indicate that the best medications would be those that both block drug-cue memory reconsolidation and augment extinction learning (Cleva et al., 2010; Sorg, 2012; Rich et al., 2016; Torregrossa and Taylor, 2016). A bidirectional effect on memory may overcome previous limitations of pharmacological agents, such as glutamatergic agonists like DCS, which are dependent on successful extinction learning (Lee et al., 2009; Price et al., 2013). In the absence of memory extinction, DCS can cause unintentional, reconsolidation-associated memory-strengthening effects, limit- 
A

IC Stimulation
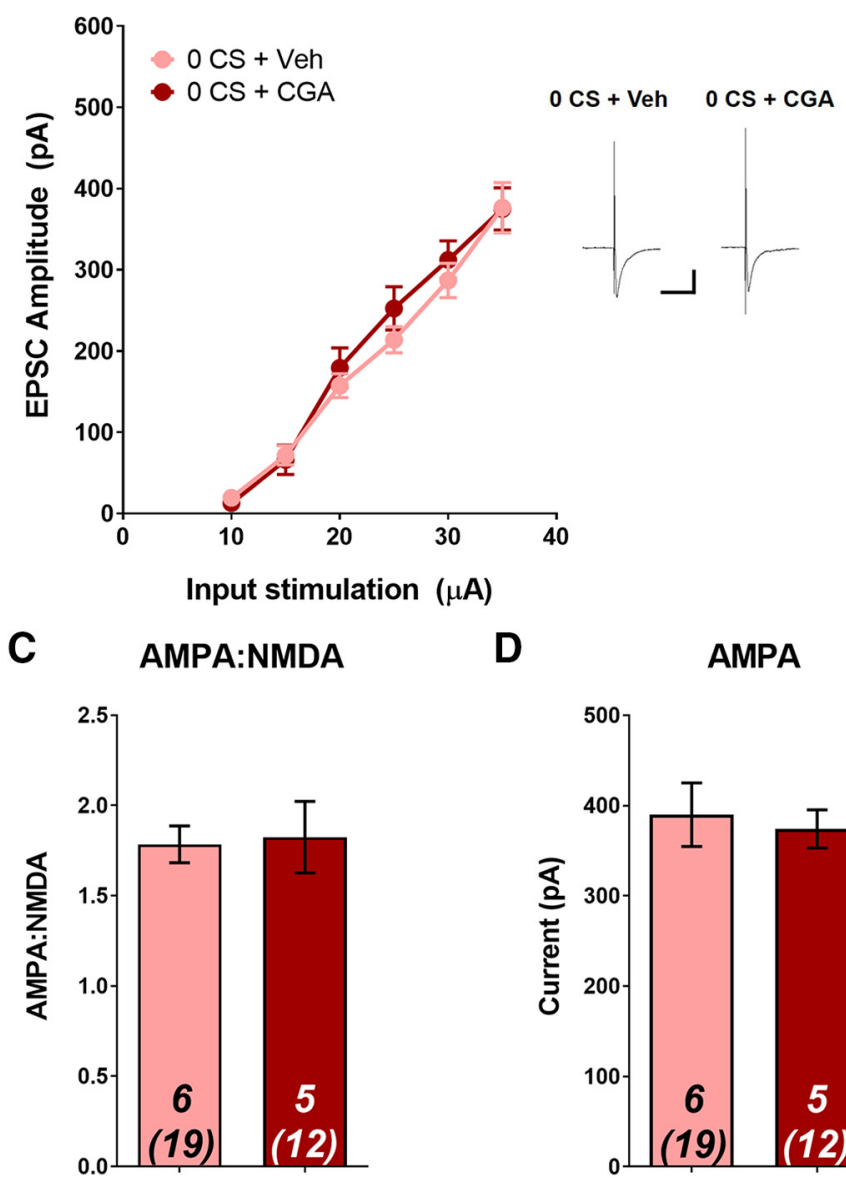

B Paired Pulse Ratio

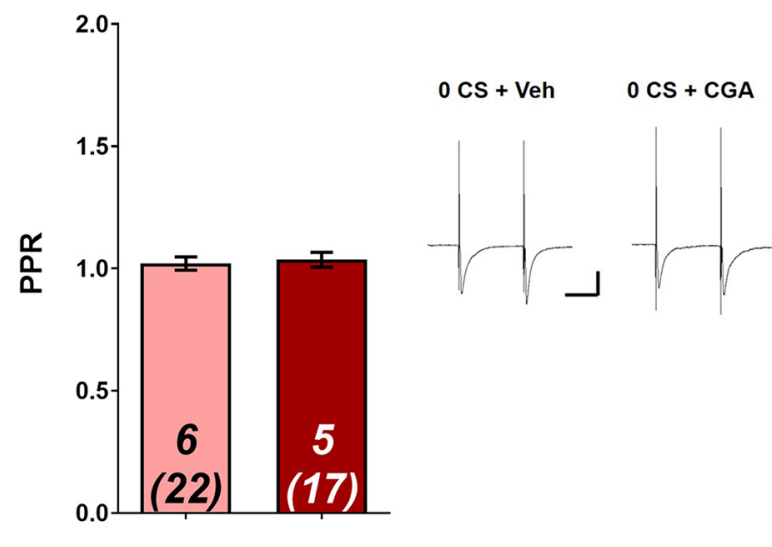

E

NMDA
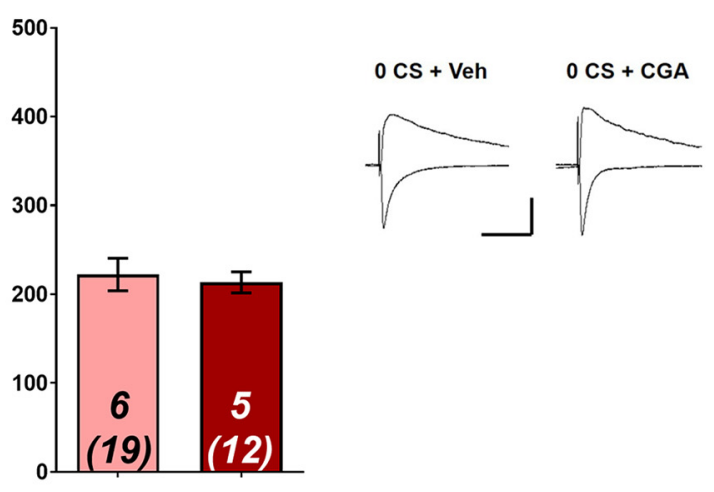

Figure 7. Calcineurin activation has no effect on T-LA plasticity in the absence of memory retrieval. Following self-administration, rats received a no-reactivation (0 CS) session followed immediately by infusion with either CGA or Veh. Twenty-four hours later, ex vivo recordings were performed in the LA. $\boldsymbol{A}$, Input/output curve demonstrating average evoked EPSC amplitude across various stimulation intensities. No significant differences in EPSC amplitude between groups were found at any of the stimulation intensities. No significant differences between groups for ( $\boldsymbol{B}$ ) PPR (C) AMPA-NMDA (D) AMPA current, or (E) NMDA current. Data are expressed as mean \pm SEM; $n$ in bars, number of rats (number of neurons). Insets, Sample average EPSC traces. Scale bars: 50 ms, $200 \mathrm{pA}$.

ing its usefulness as an adjunctive treatment (Lee et al., 2009). As we have previously demonstrated with CaMKII inhibition (Rich et al., 2016), activating CaN signaling pathways in conjunction with exposure therapy may therefore be a viable treatment strategy, because memory weakening occurs under both memory reactivation and extinction conditions.

In the current study, we demonstrate potential therapeutic effects of CaN activation following 3 (reconsolidation) or 60 (extinction) presentations of cocaine-associated cues. Previously, 120 CS presentations during re-exposure resulted in an even more pronounced AMPAR-associated depotentiation at T-LA synapses that was associated with a further suppression of cueinduced reinstatement. We did not examine the effects of $\mathrm{CaN}$ activation following this extended extinction duration because we previously failed to observe pharmacological enhancement of extinction via CaMKII inhibition, due to a potential floor effect, supported by our observation of complete synaptic depotentiation after 120 CS exposure (Rich et al., 2016, 2019). Although CGA infusions following 60 CS presentations only moderately reduces reinstatement, it is likely that cue extinction on its own already engages $\mathrm{CaN}$ to some extent. The addition of CGA may activate calcineurin beyond this physiological threshold, causing a reduction in reinstatement that is similar to levels achieved by more extensive extinction (120 CS). This is supported by the corresponding CGA-induced enhancements of synaptic depotentiation. Future studies should examine what, if any, changes occur at T-LA synapses following the activation of CaN immediately after more extensive extinction, and if the combination of extended extinction and $\mathrm{CaN}$ activation prevents either contextdependent renewal or spontaneous recovery of drug-seeking, both of which limit the therapeutic potential of cue re-exposure.

\section{Mechanisms of calcineurin action at the synapse}

$\mathrm{CaN}$ is a $\mathrm{Ca}^{2+} /$ calmodulin-dependent phosphatase with high affinity for $\mathrm{Ca}^{2+}$, allowing activation by a relatively low concentration of intracellular $\mathrm{Ca}^{2+}$. When synaptic activity is sparse (i.e., low-frequency), the primary means of $\mathrm{Ca}^{2+}$ entry is through L-type voltage-gated calcium channels, which allow for a sustained, but low increase in $\mathrm{Ca}^{2+}$ that activates $\mathrm{CaN}$ (Bi and Poo, 1998; Ghosh et al., 2017). CaN is a heterodimer composed of a catalytic A subunit and a regulatory B subunit (Mumby and Walter, 1993). Sequential conformational changes following binding of $\mathrm{Ca}^{2+}$ and calmodulin to $\mathrm{CaN}_{\mathrm{B}}$ activates the phosphatase via displacement of the $\mathrm{CaN}_{\mathrm{A}}$ auto-inhibitory domain (Shen et al., 2008). CaN then directly dephosphorylates GluA1 at Ser845, preventing kinase-induced membrane insertion of AMPAR (Roche 
et al., 1996; Beattie et al., 2000; Man et al., 2007). CaN also initiates a phosphatase cascade (via protein phosphatase 1 and protein phosphatase $2 \mathrm{~A}$ ) that ultimately leads to the inactivation of LTP-promoting kinases and downstream actions at AMPAR and other synaptic proteins (Mulkey et al., 1994; Baumgärtel and Mansuy, 2012). CaN-induced internalization of AMPAR alters spine morphology, and decreases spine density and AMPANMDA (Beattie et al., 2000; Lu et al., 2000; Sanderson et al., 2016). These changes are consistent with our present results in which CaN activation following cocaine-cue memory reactivation and extinction has effects on plasticity through a postsynaptic mechanism, including alterations in AMPAR.

$\mathrm{CaN}$ also has effects at the presynaptic membrane. For example, in the cortex, $\mathrm{CaN}$ is enriched at presynaptic terminals (Shields et al., 1985) and application of CaN inhibitors increases both the rate of spontaneous action potential firing and the frequency of EPSCs (Victor et al., 1995). Furthermore, presynaptic calcineurin has been found to be necessary for the induction of LTD at CA3-CA1 synapses in the mouse hippocampus (Andrade-Talavera et al., 2016) These data are suggestive of an inhibitory role of CaN in glutamatergic transmission and is consistent with the increase in PPR (decrease in release probability) that we observe following the activation of $\mathrm{CaN}$ during cue extinction. However, it should be noted that our previous experiments involving cocaine-cue memory extinction did not uncover any presynaptic-based changes in T-LA synaptic plasticity. Therefore, the mechanisms of CaN-induced presynaptic plasticity remain to be determined.

\section{Role for CaN in drug-associated memory processes}

$\mathrm{CaN}$ has long been established as a negative regulator of emotionallysalient memories (Baumgärtel et al., 2008; Havekes et al., 2008; de la Fuente et al., 2014), including the regulation of fear-associated memories, specifically the establishment of fear extinction. Fear extinction was shown to evoke increases in protein levels and enzymatic activity of $\mathrm{CaN}$ within the amygdala that were accompanied by the reversal of fear conditioning-induced protein phosphorylation (Lin et al., 2003a,b). These effects were blocked by the administration of $\mathrm{CaN}$ inhibitors, suggesting that $\mathrm{CaN}$ either directly or indirectly dephosphorylates specific substrates whose phosphorylation is required for the consolidation of fear-associated memories. Likewise, low-frequency stimulation of amygdala-projecting sensory cortical afferents could elicit depotentiation in the LA following fear conditioning, an effect that was blocked by administration of CaN inhibitors. (Lin et al., 2003a). The fear extinction-associated effects of CaN appear to be dependent on the amount or duration of cue reexposure. Merlo et al. (2014) demonstrated that protein levels of $\mathrm{CaN}$ increase after 10 (but not fewer) presentations of a fearassociated CS, suggesting that $\mathrm{CaN}$ helps govern the switch between maintenance and loss of fear memory. The sensitivity of $\mathrm{CaN}$ to the number of CS presentations may partly explain our failure to observe statistically significant extinction-related postsynaptic changes (i.e., a reduction in AMPAR) following CGA infusion and may also account for the lack of significant reductions in relapse-like behavior. It is possible that altering the number of CS presentations used to achieve extinction, or increasing the concentration of CGA may further unmask CGA-dependent reductions in postsynaptic signaling and lead to a significant attenuation of reinstatement.

Finally, there is evidence that $\mathrm{CaN}$ regulates drug-related memories, specifically the destabilization of a contextual memory associated with methamphetamine (METH; Yu et al., 2016). First, the reconsolidation of a METH conditioned place prefer- ence memory was disrupted with a protein synthesis inhibitor (anisomycin). Destabilization was confirmed by observations of reduced phosphorylation of GluA1 at Ser845, decreased spine density, and smaller AMPA-NMDA. Combining anisomycin treatment with inhibitors of either $\mathrm{CaN}$ or protein phosphatase 1 prevented the destabilization-associated deficits, suggesting that destabilization of drug-related contextual memories occurs through a CaN-dependent dephosphorylation cascade that results in AMPAR internalization and LTD (Mulkey et al., 1994; Yu et al., 2016). Together with the results from the present study, there is strong evidence to support that upregulation of CaN activity during cocaine-cue memory reactivation is an effective strategy for reducing the strength of drug-related memories, either through postsynaptic actions at AMPAR that block reconsolidation or by a potential combination of presynaptic and postsynaptic mechanisms that enhance extinction.

\section{References}

Andrade-Talavera Y, Duque-Feria P, Paulsen O, Rodríguez-Moreno A (2016) Presynaptic spike timing-dependent long-term depression in the mouse hippocampus. Cereb Cortex 26:3637-3654.

Baumgärtel K, Mansuy IM (2012) Neural functions of calcineurin in synaptic plasticity and memory. Learn Mem 19:375-384.

Baumgärtel K, Genoux D, Welzl H, Tweedie-Cullen RY, Koshibu K, Livingstone-Zatchej M, Mamie C, Mansuy IM (2008) Control of the establishment of aversive memory by calcineurin and Zif268. Nat Neurosci 11:572-578.

Beattie EC, Carroll RC, Yu X, Morishita W, Yasuda H, von Zastrow M, Malenka RC (2000) Regulation of AMPA receptor endocytosis by a signaling mechanism shared with LTD. Nat Neurosci 3:1291-1300.

Bi GQ, Poo MM (1998) Synaptic modifications in cultured hippocampal neurons: dependence on spike timing, synaptic strength, and postsynaptic cell type. J Neurosci 18:10464-10472.

Bossert JM, Marchant NJ, Calu DJ, Shaham Y (2013) The reinstatement model of drug relapse: recent neurobiological findings, emerging research topics, and translational research. Psychopharmacology 229:453-476.

Carelli RM, Williams JG, Hollander JA (2003) Basolateral amygdala neurons encode cocaine self-administration and cocaine-associated cues. J Neurosci 23:8204-8211.

Carroll KM, Onken LS (2005) Behavioral therapies for drug abuse. Am J Psychiatry 162:1452-1460.

Ciccocioppo R, Sanna PP, Weiss F (2001) Cocaine-predictive stimulus induces drug-seeking behavior and neural activation in limbic brain regions after multiple months of abstinence: reversal by D1 antagonists. Proc Natl Acad Sci U S A 98:1976-1981.

Cleva RM, Gass JT, Widholm JJ, Olive MF (2010) Glutamatergic targets for enhancing extinction learning in drug addiction. Curr Neuropharmacol 8:394-408.

de la Fuente V, Federman N, Fustiñana MS, Zalcman G, Romano A (2014) Calcineurin phosphatase as a negative regulator of fear memory in hippocampus: control on nuclear factor $-\kappa \mathrm{B}$ signaling in consolidation and reconsolidation. Hippocampus 24:1549-1561.

Ghosh A, Carew SJ, Chen X, Yuan Q (2017) The role of L-type calcium channels in olfactory learning and its modulation by norepinephrine. Front Cell Neurosci 11:394.

Hammond S, Wagner JJ (2013) The context dependency of extinction negates the effectiveness of cognitive enhancement to reduce cocaineprimed reinstatement. Behav Brain Res 252:444-449.

Havekes R, Nijholt IM, Visser AK, Eisel UL, Van der Zee EA (2008) Transgenic inhibition of neuronal calcineurin activity in the forebrain facilitates fear conditioning, but inhibits the extinction of contextual fear memories. Neurobiol Learn Mem 89:595-598.

Hofmann SG, Asnaani A, Vonk IJ, Sawyer AT, Fang A (2012) The efficacy of cognitive behavioral therapy: a review of meta-analyses. Cognit Ther Res 36:427-440.

Holmes A, Quirk GJ (2010) Pharmacological facilitation of fear extinction and the search for adjunct treatments for anxiety disorders: the case of yohimbine. Trends Pharmacol Sci 31:2-7.

Hsiang HL, Epp JR, van den Oever MC, Yan C, Rashid AJ, Insel N, Ye L, 
Niibori Y, Deisseroth K, Frankland PW, Josselyn SA (2014) Manipulating a "cocaine engram" in mice. J Neurosci 34:14115-14127.

Huang YH, Lin Y, Brown TE, Han MH, Saal DB, Neve RL, Zukin RS, Sorg BA, Nestler EJ, Malenka RC, Dong Y (2008) CREB modulates the functional output of nucleus accumbens neurons: a critical role of $N$-methyl-Daspartate glutamate receptor (NMDAR) receptors. J Biol Chem 283:2751-2760.

Huang YH, Lin Y, Mu P, Lee BR, Brown TE, Wayman G, Marie H, Liu W, Yan Z, Sorg BA, Schlüter OM, Zukin RS, Dong Y (2009) In vivo cocaine experience generates silent synapses. Neuron 63:40-47.

Janak PH, Tye KM (2015) From circuits to behaviour in the amygdala. Nature 517:284-292.

Kalivas PW (2009) The glutamate homeostasis hypothesis of addiction. Nat Rev Neurosci 10:561-572.

Koob GF, Volkow ND (2010) Neurocircuitry of addiction. Neuropsychopharmacology 35:217-238.

Lee JL, Gardner RJ, Butler VJ, Everitt BJ (2009) D-cycloserine potentiates the reconsolidation of cocaine-associated memories. Learn Mem 16:82-85.

Lee JL, Nader K, Schiller D (2017) An update on memory reconsolidation updating. Trends Cogn Sci 21:531-545.

Lin CH, Lee CC, Gean PW (2003a) Involvement of a calcineurin cascade in amygdala depotentiation and quenching of fear memory. Mol Pharmacol 63:44-52.

Lin CH, Yeh SH, Leu TH, Chang WC, Wang ST, Gean PW (2003b) Identification of calcineurin as a key signal in the extinction of fear memory. J Neurosci 23:1574-1579.

Lu YM, Mansuy IM, Kandel ER, Roder J (2000) Calcineurin-mediated LTD of GABAergic inhibition underlies the increased excitability of CA1 neurons associated with LTP. Neuron 26:197-205.

Man HY, Sekine-Aizawa Y, Huganir RL (2007) Regulation of [alpha]amino-3-hydroxy-5-methyl-4-isoxazolepropionic acid receptor trafficking through PKA phosphorylation of the glu receptor 1 subunit. Proc Natl Acad Sci U S A 104:3579-3584.

Maren S (2016) Parsing reward and aversion in the amygdala. Neuron 90:209-211.

Merlo E, Milton AL, Goozée ZY, Theobald DE, Everitt BJ (2014) Reconsolidation and extinction are dissociable and mutually exclusive processes: behavioral and molecular evidence. J Neurosci 34:2422-2431.

Mulkey RM, Endo S, Shenolikar S, Malenka RC (1994) Involvement of a calcineurin/ inhibitor-1 phosphatase cascade in hippocampal long-term depression. Nature 369:486-488.

Mumby MC, Walter G (1993) Protein serine/threonine phosphatases: structure, regulation, and functions in cell growth. Physiol Rev 73:673-699.

Nader K, Schafe GE, Le Doux JE (2000) Fear memories require protein synthesis in the amygdala for reconsolidation after retrieval. Nature 406:722-726.

Neisewander JL, Baker DA, Fuchs RA, Tran-Nguyen LT, Palmer A, Marshall JF (2000) Fos protein expression and cocaine-seeking behavior in rats after exposure to a cocaine self-administration environment. J Neurosci 20:798-805.

Nic Dhonnchadha BÁ, Szalay JJ, Achat-Mendes C, Platt DM, Otto MW, Spealman RD, Kantak KM (2010) D-cycloserine deters reacquisition of cocaine self-administration by augmenting extinction learning. Neuropsychopharmacology 35:357-367.

Parvaz MA, Moeller SJ, Goldstein RZ (2016) Incubation of cue-induced craving in adults addicted to cocaine measured by electroencephalography. JAMA Psychiatry 73:1127-1134.

Paxinos G, Watson C (1998) The rat brain in stereotaxic coordinates. San Diego: Academic Press.

Price KL, Baker NL, McRae-Clark AL, Saladin ME, Desantis SM, Santa Ana
EJ, Brady KT (2013) A randomized, placebo-controlled laboratory study of the effects of D-cycloserine on craving in cocaine-dependent individuals. Psychopharmacology 226:739-746.

Rich MT, Abbott TB, Chung L, Gulcicek EE, Stone KL, Colangelo CM, Lam TT, Nairn AC, Taylor JR, Torregrossa MM (2016) Phosphoproteomic analysis reveals a novel mechanism of CaMKII regulation inversely induced by cocaine memory extinction versus reconsolidation. J Neurosci 36:7613-7627.

Rich MT, Huang YH, Torregrossa MM (2019) Plasticity at thalamoamygdala synapses regulates cocaine-cue memory formation and extinction. Cell Rep 26:1010-1020.e5.

Roche KW, O’Brien RJ, Mammen AL, Bernhardt J, Huganir RL (1996) Characterization of multiple phosphorylation sites on the AMPA receptor GluR1 subunit. Neuron 16:1179-1188.

Sanderson JL, Gorski JA, Dell'Acqua ML (2016) NMDA receptor-dependent LTD requires transient synaptic incorporation of $\mathrm{Ca}^{2+}$-permeable AMPARs mediated by AKAP150-anchored PKA and calcineurin. Neuron 89:1000-1015.

Schafe GE, Nader K, Blair HT, LeDoux JE (2001) Memory consolidation of Pavlovian fear conditioning: a cellular and molecular perspective. Trends Neurosci 24:540-546.

Shabel SJ, Janak PH (2009) Substantial similarity in amygdala neuronal activity during conditioned appetitive and aversive emotional arousal. Proc Natl Acad Sci U S A 106:15031-15036.

Shen X, Li H, Ou Y, Tao W, Dong A, Kong J, Ji C, Yu S (2008) The secondary structure of calcineurin regulatory region and conformational change induced by calcium/calmodulin binding. J Biol Chem 283:11407-11413.

Shields SM, Ingebritsen TS, Kelly PT (1985) Identification of protein phosphatase 1 in synaptic junctions: dephosphorylation of endogenous calmodulin-dependent kinase II and synapse-enriched phosphoproteins. J Neurosci 5:3414-3422.

Sorg BA (2012) Reconsolidation of drug memories. Neurosci Biobehav Rev 36:1400-1417.

Ting JT, Daigle TL, Chen Q, Feng G (2014) Acute brain slice methods for adult and aging animals: application of targeted patch clamp analysis and optogenetics. Methods Mol Biol 1183:221-242.

Tong L, Song Y, Jia Z, Zhang W, Wei Q (2007) Calmodulin-dependent activation of calcineurin by chlorogenic acid. IUBMB Life 59:402-407.

Torregrossa MM, Taylor JR (2013) Learning to forget: manipulating extinction and reconsolidation processes to treat addiction. Psychopharmacology 226:659-672.

Torregrossa MM, Taylor JR (2016) Neuroscience of learning and memory for addiction medicine: from habit formation to memory reconsolidation. Prog Brain Res 223:91-113.

Torregrossa MM, Corlett PR, Taylor JR (2011) Aberrant learning and memory in addiction. Neurobiol Learn Mem 96:609-623.

Tronson NC, Taylor JR (2007) Molecular mechanisms of memory reconsolidation. Nat Rev Neurosci 8:262-275.

Tronson NC, Wiseman SL, Olausson P, Taylor JR (2006) Bidirectional behavioral plasticity of memory reconsolidation depends on amygdalar protein kinase A. Nat Neurosci 9:167-169.

Tye KM, Stuber GD, de Ridder B, Bonci A, Janak PH (2008) Rapid strengthening of thalamo-amygdala synapses mediates cue-reward learning. Nature 453:1253-1257.

Victor RG, Thomas GD, Marban E, O'Rourke B (1995) Presynaptic modulation of cortical synaptic activity by calcineurin. Proc Natl Acad Sci U S A 92:6269-6273

Yu YJ, Huang CH, Chang CH, Gean PW (2016) Involvement of protein phosphatases in the destabilization of methamphetamine-associated contextual memory. Learn Mem 23:486-493. 